\title{
Argumentação e emoção em golpes da recarga premiada: análise à luz da semiolinguística e da linguística forense ${ }^{i}$
}

\author{
Welton Pereira e Silva \\ Doutorando em Letras Vernáculas pela Universidade Federal do Rio de Janeiro (UFRJ), \\ Brasil. Bolsista CAPES, processo 001. \\ weltonp.silva@hotmail.com
}

Resumo: Este artigo analisa a utilização de argumentos patêmicos, por parte do sujeito enunciador, em "golpes da recarga premiada". Nosso corpus consiste em três gravações telefônicas obtidas a partir do YouTube que foram, posteriormente, transcritas e analisadas a partir do referencial teórico e metodológico da Teoria Semiolinguística do Discurso (CHARAUDEAU, 2010; 2010). O golpe aqui analisado pode ser considerado como um gênero discursivo, pois possui particularidades que o diferenciam de outras práticas discursivas, sendo dotado de uma relativa estabilidade. Além disso, notamos que os sujeitos estelionatários fazem uso de argumentos que procuram despertar o medo ou a alegria nos interlocutores, visando a fazer com que estes acreditem em suas afirmações, o que poderia culminar na consumação do golpe. Por lidar com uma prática discursiva considerada criminosa, este trabalho se encontra no escopo da Linguística Forense, área aplicada que relaciona a Linguística a questões de natureza judicial (OLSSON, 2008).

Palavras-chave: Argumentação. Emoção. Golpes da Recarga Premiada. Linguística Forense.

Abstract: This paper analyses the use of pathemic arguments in AWARDS RECHARGE SCAMS. Our corpus consists of three telephonic recordings obtained from YouTube. These recordings were transcribed and analyzed by the theoretical and methodological referential of the Semiolinguistic Theory of Discourse (CHARAUDEAU, 2010; 2010). This crime can be considered as a discursive genre, since it has peculiarities and practices differentiated from other discursive practices, being composed with a relative stability. In addition, it was noticed that the stellarians uses arguments that seek to arouse the fear or a joy in the interlocutors, in order to make them believe in their affirmations, which could culminate in the consummation of the crime. Because we are dealing with a crime discursive practice, this work is on the scope of Forensic Linguistics, applied area that relates Linguistics to judicial issues (OLSSON, 2008).

Keywords: Argumentation. Emotion. Awards Recharge Scams. Forensic Linguistics.

\footnotetext{
'Este artigo resulta de nossa dissertação de mestrado intitulada "A argumentação em crimes via telefone sob a perspectiva da Teoria Semiolinguística", orientada pela Profa. Dra. Mônica Santos de Souza Melo e co-orientada pelo Prof. Dr. Rony Petterson Gomes do Vale, em 2016, na Universidade Federal de Viçosa, contando com financiamento da CAPES.
} 
$\mathrm{E} \mid \mathrm{D} \overline{\mathrm{A}}$

Revista Eletrônica de Estudos Integrados em Discurso e Argumentação, Ilhéus, n. 17, jul./dez. 2018

Introdução

O presente artigo procura analisar e descrever os argumentos patêmicos utilizados pelo sujeito enunciador em "golpes da recarga premiada". Acreditamos que, na medida em que este golpe, que se configura em uma tentativa de estelionato, consiste na utilização de argumentos que visam a ludibriar as possíveis vítimas, esta prática discursiva deve ser investigada à luz da análise do discurso. De modo a atingirmos o objetivo proposto, nos guiamos pelos postulados teóricos e metodológicos da Teoria Semiolinguística do Discurso, de Patrick Charaudeau. Além disso, por estarmos investigando uma situação de comunicação passível de criminalização, estamos no arcabouço da Linguística Forense. Assim, na seção um, apresentamos a patemização no discurso como um possível objeto em pesquisas vinculadas à Linguística Forense. Na seção dois, descrevemos e configuramos o gênero discursivo "golpe da recarga premiada" e, na seção três, apresentamos nossas análises propriamente ditas.

\section{A patemização no discurso como objeto de estudo na Linguística Forense}

Desde a Retórica de Aristóteles, é aceito que determinados argumentos apresentam a capacidade de despertar certas emoções no interlocutor alvo da argumentação. Assim, ao lado do logos e do ethos, Aristóteles (2005) nos apresenta a noção de pathos ( $\pi$ áӨoৎ) como um dos integrantes do que ele chama de provas artísticas. Segundo o filósofo, "persuade-se pela disposição dos ouvintes, quando estes são levados a sentir emoção por meio do discurso, pois os juízos que emitimos variam conforme sentimos tristeza ou alegria, amor ou ódio" (ARISTÓTELES, 2005, p. 97).

Mais recentemente, diversos pesquisadores do fenômeno argumentativo, principalmente aqueles relacionados às correntes francesas de análise do discurso, recuperaram essas noções aristotélicas, adaptando-as às suas respectivas visões epistemológicas. Assim, Charaudeau (2010), ao tratar das emoções no interior da Teoria Semiolinguística do Discurso, faz uso do termo "patemização" e nos explica que o despertar, ou não, de determinadas emoções, no interlocutor, no sujeito interpretante, é dependente de diversos fatores relacionados tanto à situação de comunicação quanto aos imaginários sociodiscursivos compartilhados pelos parceiros da troca comunicativa.

De acordo com o criador da Semiolinguística: 
A análise do discurso não pode se interessar pela emoção como realidade manifesta, vivenciada por um sujeito. Ela não possui os meios metodológicos. Em contrapartida, ela pode tentar estudar o processo discursivo pelo qual a emoção pode ser estabelecida, ou seja, tratá-la como um efeito visado (ou suposto), sem nunca ter a garantia sobre o efeito produzido (CHARAUDEAU, 2010, p. 34).

Ou seja, o sujeito comunicante lança mão de determinadas estratégias patêmicas para veicular esta ou aquela emoção em seu público. Assim, o sujeito comunicante quer levar o sujeito interpretante a fazer-crer (efeito visado) em seu argumento através da visada de fazer-sentir (apresentando uma imagem, uma descrição etc). Desse modo, podemos analisar as formas, as estratégias argumentativas pelas quais ele tenta fazer com que o sujeito interpretante seja mobilizado pelo seu enunciado, mas não se, de fato, tais emoções foram despertadas.

Quanto às noções de sujeito trabalhadas no interior da Semiolinguística, é entendido que, na interação, entram em cena quatro sujeitos: dois seres sociais, o sujeito comunicante, na instância de produção do discurso, e o sujeito interpretante, na instância de recepção; e dois seres discursivos: o sujeito enunciador, que é a projeção do comunicante no discurso, e o sujeito destinatário, que diz respeito à imagem que o sujeito comunicante faz de seu interlocutor (CHARAUDEAU, 2012).

$\mathrm{Na}$ medida em que os "golpes da recarga premiada", objeto de estudo do presente artigo, configuram um tipo de crime de estelionato, essas análises contribuirão para o entendimento do funcionamento discursivo no interior de uma situação de comunicação passível de ser considerada como um crime. Devido a isso, estas análises se encontram na área de atuação da Linguística Forense, disciplina recente que se preocupa em entender a linguagem em contextos legais, como o discurso jurídico, interação no fórum, tradução legal, tomadas de depoimento, dentre outras questões. No entanto, o enfoque da Linguística Forense não recai apenas sobre questões diretamente relacionadas ao fórum e às leis. Conforme ensina Olsson:

A Linguística Forense é a aplicação do conhecimento linguístico a um ambiente social particular, nomeadamente o fórum (é daí que provém a palavra forense). Em sentido mais amplo, podemos dizer que a Linguística Forense é a interface entre linguagem, crime e lei, onde lei inclui a aplicação da lei, a matéria jurídica, a legislação, disputas ou procedimentos legais, e até mesmo disputas que só envolvem potencialmente alguma infração da lei ou alguma necessidade de 
encontrar uma solução legal (OLSSON, 2008, p. 03, tradução nossa, grifos nossos)'.

O linguista acima referenciado deixa claro que a Linguística Forense também se preocupa em investigar questões relacionadas aos crimes, principalmente aqueles que envolvem uma contraparte linguística, como o “golpe da recarga premiada". Este crime apenas se consuma caso a possível vítima deixe-se persuadir pelos argumentos do pretenso estelionatário. Deste modo, analisar e compreender a forma como os sujeitos que procuram consumar um crime fazem uso de argumentos, notadamente de teor patêmico, visando a convencer as possíveis vítimas acerca da veracidade de suas afirmações é uma contribuição singular que a análise do discurso pode fornecer à Linguística Forense.

Apesar de recente no Brasil, a Linguística Forense se encontra em próspero desenvolvimento e, aos poucos, vem ganhando espaço nas faculdades de Letras e institutos de pesquisa linguística brasileiros. A seguir, apresentaremos um pouco mais acerca do golpe aqui descrito e analisado, procurando configurá-lo como um gênero discursivo.

\section{O gênero "golpe da recarga premiada"}

O corpus de análise do presente artigo é constituído por três textos transcritos a partir de três gravações do crime de estelionato conhecido como "golpe da recarga premiada". Tais gravações foram obtidas a partir do site YouTube e as transcrevemos, procurando manter determinadas idiossincrasias linguísticas marcadas no texto, tais como marcas sociolinguísticas e dialetais. Como tais textos orais são raramente gravados e disponibilizados online, optamos por analisar aqueles que apresentavam uma qualidade digital adequada ao trabalho de pesquisa.

De acordo com o artigo 171 do Código Penal Brasileiro, é considerado estelionato a ação de "obter, para si ou para outrem, vantagem ilícita, em prejuízo alheio, induzindo ou mantendo alguém em erro, mediante artifício, ardil, ou qualquer outro meio fraudulento" (ANGHER, 2004, p. 486). A pena para esse tipo de crime pode variar entre a reclusão de um a cinco anos e multa.

\footnotetext{
${ }^{1}$ Forensic Linguistics is, rather, the application of linguistic knowledge to a particular social setting, namely the legal forum (from which the word forensic is derived). In its broadest sense we may say that Forensic Linguistics is the interface between language, crime and law, where law includes law enforcement, judicial matters, legislation, disputes or proceedings in law, and even disputes which only potentially involve some infraction of the law or some necessity to seek a legal remedy.
} 


\section{$\mathrm{EI} D \bar{\alpha} \mathrm{A}$}

Revista Eletrônica de Estudos Integrados em Discurso e Argumentação, Ilhéus, n. 17, jul./dez. 2018

É importante ressaltar, portanto, que os crimes de estelionato se caracterizam pelo ardil utilizado pelos delinquentes que pode levar a vítima a entregar-Ihes o que desejam, em nosso caso, uma quantia em dinheiro. Dessa forma, a vítima não é forçada a entregar seus bens, mas é enganada e levada a fazê-lo. Vemos, portanto, que, no estelionato, pretende-se convencer, persuadir o interlocutor, no caso, a possível vítima do crime.

O modus operandi do "golpe da recarga premiada" inicia-se a partir da chegada de uma mensagem ao celular da possível vítima, afirmando que ela é a ganhadora de um prêmio em dinheiro ou outros bens. Abaixo, podemos observar um exemplo deste tipo de mensagem que chega ao telefone celular do destinatário:

Figura 1 - Mensagem de golpe da recarga premiada

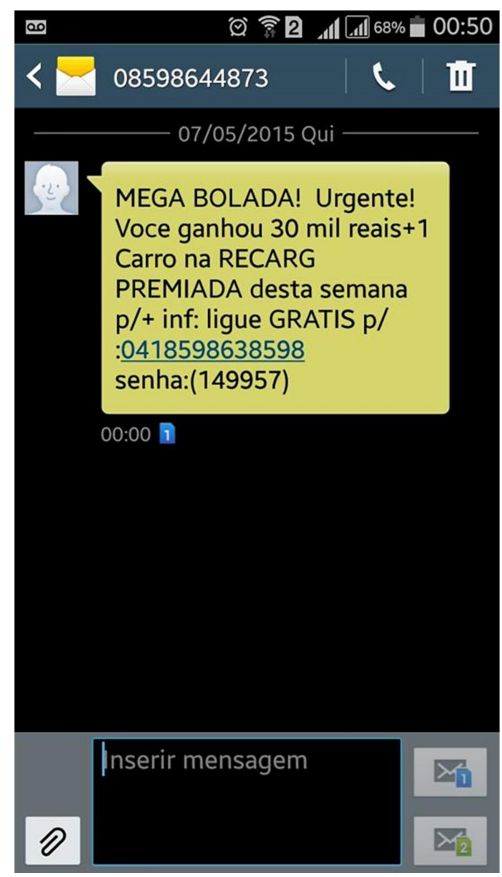

Fonte: acervo pessoal

Após o recebimento da mensagem, caso a vítima em potencial retorne a ligação para o número fornecido, o sujeito que age contra a lei passa-se por um representante da empresa beneficiadora e, após confirmar em qual banco a vítima possui conta corrente, pede que a mesma dirija-se a um caixa eletrônico de sua agência bancária. Durante a operação no caixa eletrônico, os estelionatários, utilizando-se de diferentes argumentos, ludibriam a vítima que, caso não perceba em tempo que está sendo vítima 
de um golpe, acabará por fazer a transferência de uma quantia monetária para uma conta fornecida por eles.

Notamos, no corpus de análise, que essas interações discursivas apresentam uma relativa estabilidade em seu formato, apresentando padrões de composição, tema e estilo. Ou seja, podemos considerá-las como gêneros discursivos sob uma perspectiva bakhtiniana (BAKHTIN, 2003). Ademais, se levarmos em consideração as categorias disponibilizadas por Charaudeau (2004) para distinguirmos um gênero, podemos dizer que as interações conhecidas como "golpes da recarga premiada" são passíveis de ser consideradas um gênero discursivo também pela Semiolinguística. Para essa perspectiva teórica, um gênero será assim considerado se apresentar finalidade, propósito comunicativo (tema), circunstâncias materiais, identidades evocadas que o distingue de outros gêneros e estar vinculado a uma prática social.

Assim, no que diz respeito à finalidade desse tipo de interação, ela implicará o uso das visadas discursivas de fazer-crer para fazer-fazer, já que, para a possível vítima efetuar a transferência de um determinado valor para a conta bancária fornecida pelos estelionatários, ela deve antes acreditar que foi vencedora em uma promoção. Com a finalidade de ludibriar, enganar a vítima, então, o sujeito enunciador evoca uma visada de incitação, pois eu quer "mandar fazer", mas não está em posição de autoridade e, por isso, ele só pode incitar a fazer. De acordo com Charaudeau (2004, p. 06), o eu deve, então, “'fazer acreditar' (por persuasão ou sedução) ao tu que ele será o beneficiário de seu próprio ato; tu está, então, em posição de 'dever acreditar' que, se age, é para o seu bem".

O propósito comunicativo, ou tema, gira em torno da suposta promoção e da premiação adquirida pelo sujeito destinatário, sorteado em um concurso promovido por alguma instituição. Em nosso corpus, a operadora de telefonia Oi e a emissora de televisão Globo foram as instituições mencionadas. Durante o percurso da interação, os estelionatários tentam fazer com que as vítimas dirijam-se a um caixa eletrônico e façam a simulação de uma transferência monetária para uma conta fornecida por eles. Caso a vítima não disponha de um conhecimento básico acerca do funcionamento bancário, poderá transferir o dinheiro disponível em sua conta para os estelionatários, acreditando que está 


\section{$\mathrm{EI} D \bar{\alpha} \mathrm{A}$}

Revista Eletrônica de Estudos Integrados em Discurso e Argumentação, Ilhéus, n. 17, jul./dez. 2018

cumprindo com os protocolos administrativos necessários para a liberação de seu prêmio.

Quanto às circunstâncias materiais na quais a troca comunicativa se realiza, essa interação se configura em uma ligação telefônica, instaurada por iniciativa da vítima que liga para o número remetente de uma mensagem SMS. Devido à natureza da situação de comunicação, observamos que as identidades discursivas que se constroem na troca são as de representante da empresa, na instância de produção, e vencedor da promoção, na instância de recepção.

Em dois dos textos que compõem o nosso corpus, os sujeitos interpretantes, que seriam as vítimas do golpe, tinham conhecimento acerca da natureza criminosa da interação. Com a intenção de efetuar o registro em áudio, no entanto, esses sujeitos, na vez de comunicantes, projetam a imagem de um sujeito enunciador que acredita ter sido contemplado pela promoção. Assim, a identidade discursiva de "vencedor da promoção" é encenada durante todo o processo comunicativo, sendo desvelada apenas ao final da interação. Como nosso foco de análise gira em torno dos argumentos utilizados pela parte estelionatária, que acreditava que o sujeito interpretante estava sendo ludibriado, o conhecimento das vítimas acerca da interação como a tentativa de realização de um crime não será um empecilho à análise.

Portanto, a partir da finalidade da troca comunicativa, o sujeito enunciador faz uso de determinadas visadas discursivas, bem como de alguns Modos para organizar seu discurso de forma a atingir seus objetivos, fazendo, também, algumas escolhas formais. No Quadro 1, apresentamos algumas amostras das principais recorrências textuais e discursivas encontradas nesse gênero discursivo, atentando-nos para o que Charaudeau (2004) chama de nível situacional (as visadas), nível das restrições discursivas (como o discurso é organizado) e nível da configuração textual (como o texto é construído). 


\section{$\mathrm{EI} \square \mathrm{\alpha A}$}

Revista Eletrônica de Estudos Integrados em Discurso e Argumentação, Ilhéus, n. 17, jul./dez. 2018

Quadro 1 - Restrições discursivas e formais do gênero situacional “golpe da recarga premiada"

\begin{tabular}{|c|c|c|c|c|c|}
\hline \multicolumn{2}{|c|}{$\begin{array}{c}\text { Nível Situacional } \\
\text { (visadas) }\end{array}$} & \multicolumn{2}{|c|}{$\begin{array}{c}\text { Nível das restrições } \\
\text { discursivas (Modos de } \\
\text { Organização) }\end{array}$} & \multicolumn{2}{|c|}{$\begin{array}{l}\text { Nível das restrições } \\
\text { discursivas (Modos } \\
\text { Enunciativos) }\end{array}$} \\
\hline \multirow{3}{*}{ 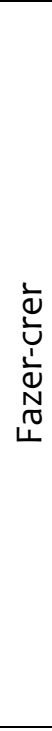 } & \multirow{3}{*}{$\begin{array}{l}\text { "O senhor vai tá } \\
\text { passando por um } \\
\text { atendente de } \\
\text { banco do } \\
\text { Bradesco que vai } \\
\text { tá liberando o } \\
\text { valor de cem mil } \\
\text { pra tua conta, tá } \\
\text { certo?." (texto 1) }\end{array}$} & \multirow{3}{*}{ 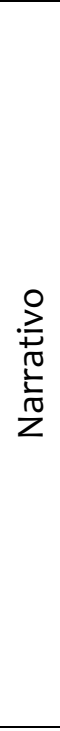 } & \multirow{3}{*}{$\begin{array}{l}\text { “No Brasil foi } \\
\text { implantado uma lei, } \\
\text { mil seiscentos e } \\
\text { noventa e nove, } \\
\text { porque nós } \\
\text { telemarketing não } \\
\text { podemos estar } \\
\text { pedindo para nossos } \\
\text { clientes nem } \\
\text { documentações } \\
\text { pessoais, nem } \\
\text { (insistindo) nada, } \\
\text { tudo bem?” (texto 2) }\end{array}$} & 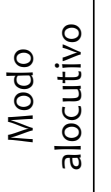 & $\begin{array}{l}\text { “Está con- está } \\
\text { contente, homem } \\
\text { de sorte?" (texto } \\
\text { 2) }\end{array}$ \\
\hline & & & & 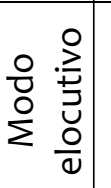 & $\begin{array}{l}\text { "Vou tá } \\
\text { transferindo a sua } \\
\text { ligação". (texto 1) }\end{array}$ \\
\hline & & & & 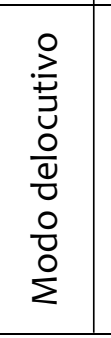 & $\begin{array}{l}\text { "O valor creditado } \\
\text { em conta e } \\
\text { aquisitivo vai ser } \\
\text { lançado para a sua } \\
\text { conta, de cento e } \\
\text { vinte mil reais." } \\
\text { (texto 3) }\end{array}$ \\
\hline \multirow{3}{*}{ 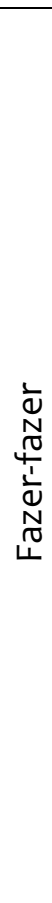 } & \multirow{3}{*}{$\begin{array}{l}\text { "o senhor, por } \\
\text { gentileza, pega } \\
\text { um papelzinho, } \\
\text { pega uma caneta } \\
\text { em mãos agora } \\
\text { de imediato pra } \\
\text { tomar ciência do } \\
\text { meu nome } \\
\text { completo." } \\
\text { (texto 3) }\end{array}$} & \multirow[b]{2}{*}{ 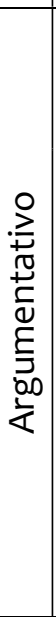 } & \multirow{2}{*}{$\begin{array}{l}\text { "Se o senhor quiser } \\
\text { estar recebendo o } \\
\text { valor de sua } \\
\text { premiação vai estar } \\
\text { vindo pra dar as } \\
\text { verdadeiras } \\
\text { informações, caso } \\
\text { não- a premiação não } \\
\text { é obrigatória, mas sim } \\
\text { opcional." (texto 2) }\end{array}$} & \multicolumn{2}{|c|}{$\begin{array}{l}\text { Nível da configuração } \\
\text { textual (composição } \\
\text { textual; vocabulário) }\end{array}$} \\
\hline & & & & 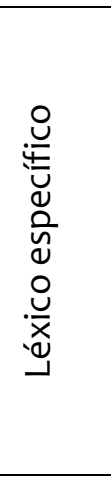 & $\begin{array}{l}\text { Cadastro } \\
\text { Protocolo } \\
\text { Senha } \\
\text { Central de } \\
\text { atendimento } \\
\text { Empresa } \\
\text { Prêmio } \\
\text { Premiação } \\
\text { Uso de } \\
\text { gerundismo } \\
\end{array}$ \\
\hline & & 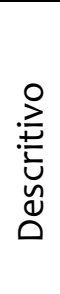 & $\begin{array}{l}\text { "É uma senha única, } \\
\text { atualmente, para o } \\
\text { terceiro ganhador e } \\
\text { contemplado da } \\
\text { promoção." (texto 2) }\end{array}$ & 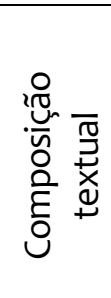 & $\begin{array}{l}\text { Anúncio do } \\
\text { prêmio } \\
\text { Fase burocrática } \\
\text { Consumação ou } \\
\text { refutação do } \\
\text { golpe }\end{array}$ \\
\hline
\end{tabular}

Fonte: Autoria própria, elaborada a partir dos dados da pesquisa.

Podemos observar que as visadas de fazer-crer para fazer-fazer foram as mais salientes, visto que os pretensos estelionatários precisam levar os sujeitos interpretantes a crer em suas palavras para aceitarem fazer a 
$\mathrm{EI} \square \mathrm{dA}$

Revista Eletrônica de Estudos Integrados em Discurso e Argumentação, Ilhéus, n. 17, jul./dez. 2018.

transferência solicitada. O Modo de Organização Narrativo mostra-se produtivo quando os enunciadores afirmam que a possível vítima foi contemplada com um prêmio, e o Modo Descritivo surge para alguma eventual explicação, como a descrição da promoção da empresa e mesmo de alguma função administrativa, como a senha, conforme vemos no caso acima. Por fim, o Modo Argumentativo se mostrou mais preponderante, visto que a finalidade principal é o convencimento da vítima acerca dos argumentos fornecidos pelo sujeito que se passa por um representante da empresa.

Quanto ao Modo Enunciativo, que influencia na organização dos demais modos (CHARAUDEAU, 2012), observa-se o uso da modalidade alocutiva (referência à segunda pessoa), já que o locutor deseja implicar o interlocutor em seu discurso, imputando-lhe uma ação e uma forma de agir. No entanto, enunciações elocutivas (referência à primeira pessoa) e delocutivas (referência à terceira pessoa) podem ser utilizadas de forma estratégica durante a encenação discursiva, como quando o estelionatário se apresenta como responsável pela liberação do prêmio ou quando se refere à empresa ou à premiação.

Quanto às marcas formais relativas ao nível da configuração textual, observa-se uma alta recorrência de termos relacionados ao campo semântico administrativo, como podemos constatar na tabela acima. Essa característica parece demonstrar um possível preparo dos sujeitos que aplicam esse golpe, embora, não raras vezes, alguns equívocos ocorram, demonstrando a falta de conhecimento acerca da esfera empresarial por parte dos sujeitos que tentam aplicar o golpe.

A partir de nossas análises, pudemos, então, destrinchar o roteiro, o modus operandi do crime. Essas diferentes partes configuram as características composicionais do gênero, bem como determinadas coerções do contrato comunicativo:

- O anúncio do prêmio: nesse primeiro momento da interação, o sujeito que procura aplicar o golpe atende o telefonema efetuado pela possível vítima e, ao ser informado de que a ligação se refere à mensagem SMS anteriormente recebida, afirma que o interlocutor foi contemplado em uma promoção de uma determinada empresa.

- A fase burocrática: caso o interlocutor acredite que foi sorteado, dáse início à segunda parte do golpe, que consiste no uso, por parte do estelionatário, de enunciados que ele julga serem pertencentes à esfera empresarial, informando dados como nomes, setores de 
atividade e senhas de protocolo. Essa fase pode servir para que a encenação discursiva torne-se mais crível para a possível vítima.

- A consumação ou refutação do golpe: após ser informado dos supostos dados, é pedido que o suposto ganhador da promoção dirija-se à agência bancária mais próxima, de modo a confirmar o recebimento de seu prêmio. Caso a possível vítima aceite dirigir-se à agência ou ao caixa eletrônico, passa-se à terceira fase, da consumação ou refutação do golpe. Já diante do caixa eletrônico, e ainda em contato com os estelionatários, a vítima pode vir a fazer uma transferência para uma conta passada pelos supostos representantes da empresa, pensando que está, na verdade, realizando uma simulação que deve ser feita para que seu prêmio seja liberado.

Dessa forma, apresentando uma finalidade específica que evoca um tema em particular, bem como determinadas identidades e circunstâncias materiais, além de estar ancorado a uma prática social homônima, o "golpe da recarga premiada" pode ser considerado como um gênero discursivo.

Na próxima seção, analisaremos a forma como os sujeitos que procuram aplicar o golpe organizam e utilizam seus argumentos patêmicos de modo a atingir seus objetivos.

\section{Argumentação patêmica em um crime de estelionato via telefone}

Nos "golpes da recarga premiada", o sujeito comunicante procura levar o sujeito interpretante a experienciar diversos tipos de emoções. Alguns desses argumentos, que se configuram a partir de determinadas estratégias patêmicas, são propícios a despertar o temor no interlocutor. Observe o seguinte exemplo:

(a) Se o senhor quiser estar recebendo o valor de sua premiação, vai estar vindo pra dar as verdadeiras informações, caso não, a premiação não é obrigatória, mas sim opcional. Se o senhor está desconfiando da nossa empresa e o que está divulgando, boa sorte na próxima premiação, tudo bem? (Texto 1 do corpus).

Em um dado momento da interação, os estelionatários desconfiam de que a vítima não tenha passado algumas informações referentes ao seu saldo bancário de forma verídica, o que os levou a fazer essa ameaça: caso o interlocutor não passasse as informações verdadeiras, ele não receberia a premiação que, segundo o sujeito que se passa pelo representante da 
empresa realizadora da promoção, não é obrigatória. Já que toda a situação de comunicação gira em torno da suposta premiação, a vítima certamente sentir-se-ia atemorizada com a possibilidade de não ter seu prêmio liberado.

É importante observar que, caso o interlocutor tivesse um conhecimento mais aprofundado acerca de premiações e transações bancárias, ele poderia ter notado que, para receber um valor monetário ao qual se tem direito, não é necessário que o saldo atual de sua conta bancária seja fornecido à empresa realizadora da promoção. Em outro momento dessa interação, ocorre algo parecido, com a mesma finalidade de amedrontar a possível vítima:

(b) Se o senhor quiser estar recebendo o valor da premiação de setenta e cinco mil, vai saindo mesmo agora para a agência bancária a qual o senhor é cliente. Caso não... (Texto 1 do corpus).

O excerto acima mostra a ocasião em que o sujeito enunciador faz uma ameaça subentendida com a falta de complemento na oração "caso não...", para fazer com que seu interlocutor aja de acordo com as instruções. Nessa parte da interação, ao ser informado de que deveria se deslocar a um caixa eletrônico para confirmar o recebimento do prêmio, o interlocutor afirma que poderá fazer todo o processo bancário sem sair de casa, através de seu laptop. Percebendo que a possibilidade de consumação do golpe estava ameaçada, o sujeito, na vez de representante da empresa, produz o enunciado acima, que não condiz com a imagem de profissional que ele desejava demonstrar, já que o funcionário de uma empresa não deveria fazer ameaças veladas a um suposto cliente.

A partir dos exemplos acima, podemos notar que um conhecimento mais aprofundado acerca do funcionamento bancário pode ser fator crucial para fazer com que as possíveis vítimas dos "golpes da recarga premiada" percebam a natureza criminosa da interação e não realizem o que os estelionatários pedem, de modo a não consumarem o golpe e não serem lesionadas.

Além de argumentos que procuram despertar sentimentos relacionados ao medo e ao temor, observamos, também, a ocorrência de argumentos que visam a despertar a alegria, a felicidade nas vítimas dos "golpes da recarga premiada”. Apresentamos, por exemplo, o excerto abaixo:

(c) Neste exato momento é momento mágico, é mudança de vida, é a Rede Globo realizando mais um sonho de mais um cidadão brasileiro. $O$ coração e a emoção no momento tá assim ou tá a mil, o coração? (Texto 2 do corpus).

No excerto acima, notamos o apelo feito às emoções do sujeito interpretante, que está passando por um "momento mágico" de "mudança 
de vida" proporcionado supostamente pela Rede Globo. Podemos observar a insistência na utilização de vocábulos como "sonho", "coração", "emoção", e ainda o uso da enunciação da expressão patêmica (CHARAUDEAU, 2010), através da enunciação alocutiva, com a finalidade de produzir um estado patêmico a partir da menção ao estado emocional no qual o sujeito destinatário se encontra, ou deveria se encontrar.

Em outro texto, também encontramos um argumento patêmico que procura despertar a alegria, a felicidade no interlocutor:

(d) ok, meus parabéns campeão, comemora, faz a festa, a Oi tá entrando em contato agora. (Texto 3 do corpus).

Novamente, através da modalidade alocutiva, ou seja, através da interpelação do interlocutor, através do vocativo "campeão" - com alto valor axiológico - e dos verbos no imperativo, "comemora", "faz", notamos que o sujeito que argumenta procura levar o destinatário a um estado de euforia. Afinal, ele deve comemorar por ser um campeão para o qual a empresa de telefonia Oi está ligando.

Não podemos deixar de notar o embasamento do argumento acima nos imaginários sociodiscursivos relacionados à mídia brasileira, que possui muitas atrações televisivas que se apoiam sobre a "realização de sonhos" de "cidadãos brasileiros", desde uma mudança no estilo de se vestir, à entrega de casas próprias ou outras aquisições de alto valor monetário. Notamos que a utilização do operador argumentativo "mais" em "mais um sonho de mais um cidadão" evoca, justamente, esse imaginário que diz que essas empresas auxiliam e realizam os sonhos de várias pessoas.

Levando em conta as fases do processo interacional dos "golpes da recarga premiada", observamos um equilíbrio no que concerne ao uso de argumentos patêmicos que procuram despertar a alegria nas possíveis vítimas, visto que, tanto na parte inicial da interação, no anúncio do prêmio, quanto na fase burocrática, os estelionatários procuram deixar claro que o seu interlocutor é um felizardo, vencedor, alguém que deve se alegrar por ser o ganhador de um alto valor monetário. Essa estratégia de captação faz-se relevante na medida em que o sucesso do golpe é dependente do fato de o interlocutor acreditar nos argumentos do locutor e passar as informações pessoais necessárias acreditando que, assim, terá posse do valor da premiação.

Por questões relativas às dimensões e objetivos deste manuscrito, não apresentamos todas as análises concernentes aos argumentos patêmicos 
encontrados nos discursos que compõem nosso corpus de análise, mas apenas utilizamos alguns como exemplo. Acreditamos, no entanto, que esses poucos exemplos já sirvam para comprovar o que procuramos demonstrar: os sujeitos enunciadores dos "golpes da recarga premiada" fazem uso de diferentes argumentos patêmicos visando a captar seus destinatários, procurando persuadir as possíveis vítimas do golpe para que elas acreditem em suas afirmações.

Estamos, então, diante de uma tentativa de crime de estelionato que utiliza aspectos linguístico-discursivos como materiais para efetivar o crime. Portanto, dada a natureza do objeto analisado enquanto corpus de pesquisa, este trabalho, que se guiou pelos pressupostos teóricos e metodológicos da Teoria Semiolinguística do Discurso, encontra-se no escopo da Linguística Forense enquanto disciplina que se ocupa da aplicação de teorias linguísticas diversas à resolução de problemas de caráter jurídico. Tal caráter é atestado pelo fato de este artigo investigar uma prática interacional passível de criminalização: o "golpe da recarga premiada".

\section{Considerações Finais}

A partir da análise do nosso corpus, constituído por textos oriundos da transcrição de três gravações de "golpes da recarga premiada", disponibilizadas no YouTube, pudemos notar que os sujeitos que procuram consumar o golpe fazem uso de diferentes argumentos patêmicos. Dentre esses argumentos, notamos que alguns procuram despertar o medo, o temor, e outros, a alegria nos interlocutores. Tais emoções são coerentes com o projeto de fala, já que, para convencer os interlocutores a efetuar a transação financeira e consumar o crime de estelionato, os sujeitos que argumentam precisam convencê-los de que foram os vencedores de um prêmio (alegria) e que, se não seguirem suas recomendações, poderão perder tal premiação (temor).

Além disso, observamos que os "golpes da recarga premiada" exibem uma relativa estabilidade em seu formato, apresentando três fases distintas: o anúncio do prêmio; a fase burocrática; e a consumação/refutação do golpe. A finalidade comunicativa, o tema, as circunstâncias materiais nas quais a troca comunicativa se realiza, bem como as identidades que emergem da situação também fazem com que esse golpe se distinga de outros usos discursivos. Ou seja, podemos considerar o "golpe da recarga premiada" como um gênero do discurso.

Este trabalho insere-se no âmbito de um projeto maior que vem sendo construído desde o nosso curso de mestrado e se estende, agora, no curso de 
$\mathrm{El} \square \mathrm{dA}$

Revista Eletrônica de Estudos Integrados em Discurso e Argumentação, Ilhéus, n. 17, jul./dez. 2018.

doutorado em Letras Vernáculas na UFRJ². Acreditamos que a compreensão detalhada do funcionamento argumentativo no interior de práticas passíveis de criminalização, tal como a que aqui foi descrita e analisada, pode servir para que compreendamos melhor a natureza de tais condutas desviantes, o que poderá culminar em políticas de segurança pública que visem ao combate a tais práticas. Por estarmos analisando uma situação de comunicação de natureza delituosa, este trabalho se encontra no escopo da Linguística Forense.

\section{Referências}

ANGHER, Anne Joyce. Código Penal. Código de Processo Penal. Constituição Federal. São Paulo: Editora Rideel, 2004.

ARISTÓTELES. Retórica. 2. ed. Lisboa: Imprensa Nacional Casa da Moeda, 2005.

BAKHTIN, Mikhail. Estética da Criação Verbal. 4. ed. São Paulo: Martins Fontes, 2003.

CHARAUDEAU, Patrick. Visadas discursivas, gêneros situacionais e construção textual. In: MACHADO, Ida Lucia; MELLO, Renato de (org.). Gêneros: reflexões em análise do discurso. Belo Horizonte: NAD/FALE/UFMG, 2004. p. 13-41.

. A patemização na televisão como estratégia de autenticidade. In: MENDES, Emília; MACHADO, Ida Lúcia, As emoções no discurso, v. II. Campinas: Mercado das Letras, 2010.

. Linguagem e discurso: modos de organização. São Paulo: Contexto, 2012.

OLSSON, John. Forensic Linguistics. New York: Continuum, 2008.

\section{Forma de citação sugerida}

SILVA, Welton Pereira e. Argumentação e emoção em golpes da recarga premiada: análise à luz da semiolinguística e da linguística forense. EID\&A - Revista Eletrônica de Estudos Integrados em Discurso e Argumentação, Ilhéus, n. 17, p. 158-171, jul./dez.2018. DOI dx.doi.org/10.17648/eidea-17-1807.

\footnotetext{
${ }^{2}$ A pesquisa em curso está sob a orientação da Professora Doutora Lúcia Helena Martins Gouvêa e também conta com o apoio financeiro da Capes.
} 